\title{
Korean Medication Algorithm for Schizophrenia 2019, Second Revision: Treatment of Psychotic Symptoms
}

\author{
Jung Suk Lee', Je-Yeon Yun ${ }^{2,3}$, Shi Hyun Kang ${ }^{4}$, Seung Jae Lee ${ }^{5}$, Joon-Ho Choi ${ }^{6}$, Beomwoo Nam ${ }^{7}$, \\ Seung-Hwan Lee ${ }^{8}$, Young-Chul Chung ${ }^{9}$, Chan-Hyung Kim ${ }^{10}$ \\ ${ }^{1}$ Department of Psychiatry, National Health Insurance Service Ilsan Hospital, Goyang, ${ }^{2}$ Department of Psychiatry, Seoul National University \\ Hospital, Seoul, ${ }^{3}$ Yeongeon Student Support Center, Seoul National University College of Medicine, Seoul, ${ }^{4}$ Department of Adult Psychiatry, \\ National Center for Mental Health, Seoul, ${ }^{5}$ Department of Psychiatry, School of Medicine, Kyungpook National University, Daegu, ${ }^{6}$ Department \\ of Psychiatry, Hanyang University College of Medicine and Mental Health Institute, Seoul, ${ }^{7}$ Department of Psychiatry, Konkuk University School \\ of Medicine, Chungju, ${ }^{8}$ Department of Psychiatry, Inje University Ilsan Paik Hospital, Goyang, ${ }^{9}$ Department of Psychiatry, Chonbuk National \\ University Medical School, Jeonju, ${ }^{10}$ Institute of Behavioral Science in Medicine and Department of Psychiatry, Yonsei University College of \\ Medicine, Seoul, Korea
}

\begin{abstract}
Objective: In 2001, the Korean College of Neuropsychopharmacology and the Korean Society for Schizophrenia Research developed the Korean Medication Algorithm Project for Schizophrenia (KMAP-SPR 2001, revised 2006) through a consensus of expert opinion. The present study was carried out to support the second revision of the KMAP-SPR.

Methods: Based on clinical guidelines and studies on the treatment of psychotic symptoms in schizophrenia, the Executive committee completed a draft of KMAP-SPR 2019. To obtain an expert consensus, a Review committee of 100 Korean psychiatrists was formed and 69 responded to a 30-item questionnaire. Based on their responses, the KMAP-SPR 2019 was finalized.

Results: The revised schizophrenia algorithm now consists of 5 stages. At Stage 1, monotherapy with atypical antipsychotics was recommended by expert reviewers as the first-line strategy. At Stage 2, most reviewers recommended the use of typical or atypical antipsychotic drugs not used at Stage 1. At Stage 3, many reviewers agreed with the administration of clozapine. At Stage 4, a combination of clozapine and other agents such as antipsychotics, mood stabilizers, antidepressants, or electroconvulsive therapy was recommended. At Stage 5, most reviewers recommended combined treatment with an antipsychotic other than clozapine; and a mood stabilizer, antidepressant, or electroconvulsive therapy. At any stage, prescribing long-acting injectable antipsychotics at the discretion of the clinician was recommended.

Conclusion: Compared with previous versions, the KMAP-SPR 2019 now recommends using clozapine earlier in treatment-refractory schizophrenia. In addition, the use of long-acting injectable antipsychotics is now considered to be available at any stage.
\end{abstract}

KEY WORDS: Schizophrenia; Algorithm; Drug therapy; Consensus; Practice guideline.

\section{INTRODUCTION}

Medication algorithms can help clinicians make decisions by providing a wealth of information about psycho-

Received: December 18, 2019/Revised: January 28, 2020 Accepted: March 12, 2020

Address for correspondence: Chan-Hyung Kim Department of Psychiatry, Severance Hospital, Yonsei University College of Medicine, 50-1 Yonsei-ro, Seodaemun-gu, Seoul 03722, Korea

E-mail: spr88@yuhs.ac

ORCID: https://orcid.org/0000-0001-8419-3759 tropic medications and research data [1]. Although treatment algorithms and clinical practice guidelines have been published in many countries, the guidelines for pharmacological treatment can vary from country to country because national health systems, economic situations, and cultural environments can differ. Most medication algorithms rely on the evidence of randomized controlled trials, but incorporating expert consensus is also important because this can lead to an algorithm reflective of national characteristics [2,3].

In order to develop medication algorithms suitable for

(ㄷ) This is an Open-Access article distributed under the terms of the Creative Commons Attribution Non-Commercial License (http://creativecommons.org/licenses/by-nc/4.0) which permits unrestricted non-commercial use, distribution, and reproduction in any medium, provided the original work is properly cited. 
clinical situations in Korea, the Korean College of Neuropsychopharmacology (KCNP) and the Korean Society for Schizophrenia Research (KSSR) developed the Korean Medication Algorithm Project for Schizophrenia (KMAP-SPR) through a consensus of expert opinion in 2001, which was updated in 2006. However, since the publication of KMAP-SPR 2006, several international clinical guidelines have been revised [4-9], new antipsychotic drugs have been developed [10-12], and studies have been published supporting the use of long-acting injectable antipsychotics (LAIs) in first-episode schizophrenia [13]. Accordingly, the KCNP and KSSR have now created a second revision, the KMAP-SPR 2019, to reflect changes in expert opinion regarding the treatment of psychotic symptoms in patients with schizophrenia.

Common to the KMAP-SPR series is a three-part organization: 1) treatment of psychotic symptoms, 2) treatment of comorbidities, and 3) treatment of adverse effects from antipsychotic medication. We aimed to determine an expert consensus on a draft revision of KMAP-SPR that reflected developments since 2006, for incorporation into a finalized second revision, with emphasis on Part 1).

\section{METHODS}

\section{Executive Committee}

This committee performs several practical tasks for medication algorithm development. There are two chairpersons, one of whom is head director of the KCNP and the other, head director of the KSSR. In addition to the chairpersons, the Committee includes three KCNP members and four KSSR members. The Executive committee recruits the members of the Review committee.

The Executive committee completed a draft version of KMAP-SPR 2019 based on various clinical guidelines and on published studies on the treatment of psychotic symptoms in schizophrenia. To gather expert opinion, they also wrote a questionnaire about the draft version and circulated it to the Review committee for comments.

\section{Review Committee}

The Executive committee recruited 100 Korean psychiatrists who were life-long members of KCNP or KSSR and had more than 10 years of clinical experience in the field of schizophrenia. Through discussion, candidates who were considered clinically and investigationally ex- perienced in the field were selected by the Executive committee. The questionnaire was mailed to members of this committee and responses were received from 69 $(69.0 \%)$ members. The respondents worked in a wide variety of clinical settings, including university hospitals ( $\mathrm{n}=$ 50), general/psychiatric hospitals $(n=17)$, and private psychiatric clinics $(\mathrm{n}=2)$.

\section{Questionnaire}

The KMAP-SPR 2019 questionnaire was similar to that used to develop the KMAP-SPR 2006, with some modifications. To take advantage of both evidence-based and expert-consensus guidelines, the questionnaire was structured as requests for comments on the draft of KMAP-SPR 2019, which was based only on evidence at that stage. Specifically, the questions asked how satisfied the reviewers were with the treatments recommended at each stage, or what treatments they would prefer. Degree of satisfaction was measured on a five-point scale. Five indicated "very satisfied," 4 indicated "usually satisfied", 3 indicated "moderate", 2 indicated "usually unacceptable" and 1 indicated "absolutely unacceptable". In questions answered with 1 or 2 points, the reviewers were asked to give their recommendations as free-form statements. The questionnaire had 30 questions. Fifteen concerned either the overall composition of the medication algorithm or the treatment of psychotic symptoms, and the remainder concerned treatment of comorbidities and adverse effects. The new modifications of the questionnaire were: In Stage 1 , the Executive committee proposed monotherapy with second-generation antipsychotics (SGAs) as the first-line treatment, and asked the reviewers which SGA they prefer. In Stage 4, the Executive committee proposed as the treatment of choice a combination therapy consisting of clozapine plus other treatments such as first-generation antipsychotics (FGAs), SGAs, mood stabilizers, antidepressants, or nonpharmacological treatments such as electroconvulsive therapy (ECT). The reviewers were also asked which treatment option they would prefer to combine with clozapine.

\section{Public Hearing}

On April 20, 2018, at the Spring Conference of the Korean Society for Neuropsychiatry, a public hearing for the development of the KMAP-SPR 2019 was held. Various proposals raised at the hearing were reviewed by 


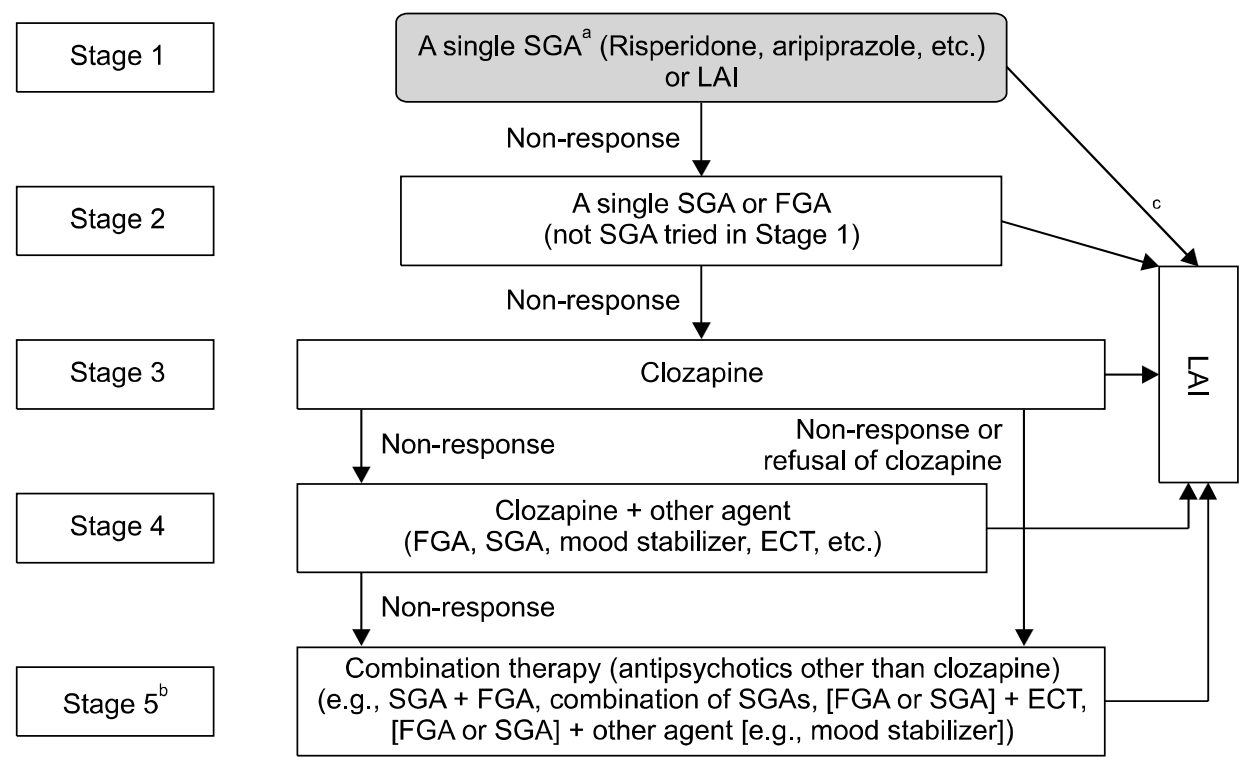

Fig. 1. Korean Medication Algorithm for Schizophrenia 2019: treatment of psychotic symptoms.

SGA, second generation antipsychotics; LAI, long-acting injectable antipsychotics; FGA, first generation antipsychotics; ECT; electroconvulsive therapy. ${ }^{a}$ Other SGAs including olanzapine, amisulpride, quetiapine, ziprasidone, paliperidone, blonanserin, zotepine are approved and used currently in South Korea. ${ }^{b}$ Depending on the clinical situation, it is possible to move to Stage 5 at any Stage. ${ }^{c}$ Depending on the clinical judgment, LAI can be considered at any Stage; Depending on the clinical situation, it is possible to skip to the further stage.

the Executive committee and the KMAP-SPR 2019 was then finalized.

\section{Data Analysis and Development of Medication Algorithms}

For each question, we counted how many reviewers gave particular scores. If a question received more than 4 points, it was considered that the reviewer was generally satisfied with the treatment option being proposed. If more than $50 \%$ of the respondents gave more than 4 points, it implies that the reviewers reached a consensus on the question. Recommendations at each stage were based on a draft prepared by the Executive committee based on various clinical guidelines and published studies, but amendments have been made if expert consensus was not reached on a particular item.

\section{Ethics}

The present study was conducted according to the Declaration of Helsinki. All reviewers received a predetermined fee for their participation.

\section{RESULTS}

\section{Overview}

As shown in Figure 1, the medication algorithm for treatment of psychotic symptoms consists of five stages. In order not to limit clinical judgment, however, clinicians can skip a stage depending on the clinical situation. As far as possible, antipsychotic monotherapy is recommended. The new parts of the KMAP-SPR 2019 are revisions to Stage 2 and the criteria for LAls (Table 1).

\section{Stage 1}

The Executive committee had proposed SGA monotherapy as the first-line treatment for psychotic symptoms. In addition, they had proposed LAls at Stage 1 if tolerance to oral medication is demonstrated. The reviewers favored risperidone $(29.9 \%)$, aripiprazole $(28.4 \%)$, olanzapine $(16.4 \%)$, and paliperidone $(14.9 \%)$ for SGA monotherapy at Stage 1 (Table 2).

\section{Stage 2}

The Executive committee had proposed that if there is no response to the SGA selected at Stage 1, another SGA or FGA monotherapy can be tried at Stage 2. Of the 69 reviewers who answered the question for Stage 2, 62 were 
Table 1. Comparisons of treatment strategies for psychotic symptoms between the Korean Medication Algorithm for Schizophrenia 2006 and 2019

\begin{tabular}{lll}
\hline & \multicolumn{1}{c}{ First revision in 2006 } & \multicolumn{1}{c}{ Second revision in 2019 } \\
\hline Stage 1 & SGA & SGA \\
Stage 2 & SGA (not tried in Stage 1) or FGA & SGA (not tried in Stage 1) or FGA \\
& With no response to a single trial of SGA or FGA, another trial & With no response to a single trial of SGA or FGA, proceed \\
of a different generation antipsychotic drug can be done & to Stage 3 \\
Clozapine \\
Stage 3 & Clozapine & Clozapine + other agent (FGA/SGA, MS, ECT, etc.) \\
Stage 4 & Clozapine + other agent (FGA/SGA, MS, ECT, etc.) & Combination therapy \\
Stage 5 & Combination therapy & Depending on the clinical judgment \\
LAI & No response due to non-compliance &
\end{tabular}

SGA, second generation antipsychotics; FGA, first generation antipsychotics; MS, mood stabilizer; ECT, electroconvulsive therapy; LAI, long-acting injectable antipsychotics.

Table 2. Preference rate and ranking of antipsychotics for Stage 1

\begin{tabular}{lccr}
\hline Antipsychotics & First place & Second place & Third place \\
\hline Risperidone & $29.9 \%(1)$ & $14.9 \%(4)$ & $10.4 \%(4)$ \\
Aripiprazole & $28.4 \%(2)$ & $16.4 \%(3)$ & $25.4 \%(1)$ \\
Olanzapine & $16.4 \%(3)$ & $34.3 \%(1)$ & $13.4 \%(3)$ \\
Paliperidone & $14.9 \%(4)$ & $17.9 \%(2)$ & $9.0 \%(6)$ \\
Blonanserin & $4.5 \%(5)$ & $1.5 \%(7)$ & $3.0 \%(7)$ \\
Amisulpride & $3.0 \%(6)$ & $6.0 \%(5)$ & $23.9 \%(2)$ \\
Quetiapine & $3.0 \%(7)$ & $6.0 \%(5)$ & $10.4 \%(4)$ \\
Ziprasidone & - & - & $1.5 \%(8)$ \\
\hline
\end{tabular}

Data are presented as preference rate (ranking).

-, not available.

satisfied (usually satisfied 37, very satisfied 25). According to the KMAP-SPR 2006, if there is no response to a single trial of SGA or FGA, another different-generation antipsychotic drug can be tried. However, according to the KMAP-SPR 2019, if there is no response to a single trial of SGA or FGA monotherapy, proceeding to Stage 3 is recommended.

\section{Stage 3}

The Executive committee had proposed clozapine monotherapy as the treatment of choice at Stage 3. Of the 69 reviewers who answered the question for Stage 3, 48 were satisfied (usually satisfied 45, very satisfied 3). Because there should be no response to two adequate trials of antipsychotic drugs before proceeding to Stage 3, reaching Stage 3 can be considered treatment resistance. When asked whether to test serum clozapine levels at this point, 35 out of 67 respondents (52.2\%) were opposed.

\section{Stage 4}

The Executive committee had proposed that when patients do not show an adequate response to clozapine,
Table 3. Preference of combination strategies for Stage 4

\begin{tabular}{cc}
\hline \multicolumn{1}{c}{ Strategies } & Preference rate \\
\hline Clozapine + SGA & $91.0 \%$ \\
Clozapine + MS & $6.0 \%$ \\
Clozapine + ECT & $1.5 \%$ \\
Clozapine + LAI & $1.5 \%$ \\
\hline
\end{tabular}

SGA, second generation antipsychotics; MS, mood stabilizer; ECT, electroconvulsive therapy; LAI, long-acting injectable antipsychotics.

Table 4. Preference of atypical antipsychotics for Stage 4

\begin{tabular}{lccc}
\hline Antipsychotics & First place & Second place & Third place \\
\hline Amisulpride & $36.5 \%(1)$ & $26.0 \%(2)$ & $20.0 \%(2)$ \\
Aripiprazole & $32.7 \%(2)$ & $28.0 \%(1)$ & $17.8 \%(3)$ \\
Risperidone & $23.1 \%(3)$ & $12.0 \%(4)$ & $28.9 \%(1)$ \\
Paliperidone & $5.8 \%(4)$ & $20.0 \%(3)$ & $8.9 \%(5)$ \\
Olanzapine & $1.9 \%(5)$ & $6.0 \%(5)$ & $6.7 \%(6)$ \\
Quetiapine & - & $6.0 \%(5)$ & - \\
Blonanserin & - & $2.0 \%(7)$ & $11.1 \%(4)$ \\
Ziprasidone & - & & $6.7 \%(6)$ \\
\hline
\end{tabular}

Data are presented as preference rate (ranking).

-, not available.

combination therapy with clozapine plus other treatments is the treatment of choice. The other agents are FGA, SGA, mood stabilizers, antidepressants, or nonpharmacological treatments such as ECT. As shown in Table 3, $91.0 \%$ of reviewers preferred a combination of clozapine and an SGA at this stage. The SGAs most preferred for combination with clozapine were amisulpride $(36.5 \%)$, aripiprazole $(32.7 \%)$, and risperidone $(23.1 \%)$ (Table 4).

\section{Stage 5}

The Executive committee had proposed that there is no treatment of choice for treatment-resistant patients who 
refuse to take clozapine or who do not respond to clozapine. Therefore, at Stage 5, various combination therapies including an SGA combined with an FGA, a combination of SGAs, an FGA/SGA with ECT, or an FGA/SGA combined with another agent (e.g., mood stabilizer, antidepressant) can be tried. Of the 69 reviewers who answered the question for Stage 5, 60 were satisfied (usually satisfied 43, very satisfied 17).

\section{LAls}

In the KMAP-SPR 2006, LAls were recommend only in cases of no treatment response due to drug non-compliance. The draft revision recommended that LAIs be prescribed at any stage at the clinician's discretion after tolerance to oral medication is verified. Of the 69 reviewers who answered the question on LAls, 59 were satisfied (usually satisfied 27 , very satisfied 32 ).

\section{Switching Strategy}

The Executive committee had proposed that the preferred switching strategy be "overlap and taper," which means continuing the same dose of the first antipsychotic while gradually increasing that of the second to a therapeutic level and then tapering the first. Of the 69 reviewers who answered the question on switching strategy, 55 were satisfied (usually satisfied 49, very satisfied 6).

\section{DISCUSSION}

\section{Evidence-based vs. Consensus-based Guidelines}

Guidelines on treatment fall into two types: expert consensus and evidence-based, each with advantages and disadvantages. The consensus among experts has the advantage of reflecting national characteristics such as health care policy, the economic situation, and ethnicity. Expert consensus statements can also provide practicebased evidence in the absence of high-quality research evidence. However, expert-consensus guidelines have in common a difficulty in guaranteeing validity. On the other hand, most evidence-based guidelines rely on randomized controlled trials (RCTs) with strict inclusion and exclusion criteria that apply only to the specific populations so defined, and conclusions from RCTs often cannot be generalized to the diverse populations seen in clinical practice. The present guideline is based mostly on expert consensus, but the recommendations for Stage 1 and
Stage 4 are based on new research. Since this guideline combines expert consensus with research evidence, it will be necessary to make further revisions if warranted by new knowledge, new high-level evidence, or experience over time, all of which must be monitored on an ongoing basis.

\section{Stage 1}

As in the KMAP-SPR 2001 and 2006, SGA monotherapy is the first-line treatment strategy for psychotic symptoms in the KMAP-SPR 2019. It has been widely accepted that SGAs should be used as the first-line drug. However, paradigms changed after some large-scale studies such as Clinical Antipsychotic Trials for Intervention Effectiveness (CATIE) [14] and Cost Utility of the Latest Antipsychotic drugs in Schizophrenia Study (CUtLASS) [15] emphasized that certain SGAs are not superior to certain FGAs regarding effectiveness. Despite these findings, we decided to use SGA as the first-line treatment for the following two reasons: First, FGAs have a high risk of extrapyramidal side effects. These side effects are one of the major causes of poor drug compliance and decreased quality of life $[16,17]$. In particular, FGAs are known to produce numerous irreversible side effects such as tardive dyskinesia, as well as life-threatening side effects such as neuroleptic malignant syndrome. At present, the most important known principle for preventing tardive dyskinesia is to minimize exposure to FGAs. Second, a meta-analysis showed that SGAs were superior to FGAs regarding relapse prevention [18].

\section{Stage 2}

According to the KMAP-SPR 2006, after a single trial of an SGA or FGA, another antipsychotic of a different generation can be tried, but in the KMAP-SPR 2019, a single trial of any SGA or FGA is recommended at Stage 2. This is consistent with other clinical guidelines such as the Schizophrenia Patient Outcomes Research Team (PORT) psychopharmacological treatment recommendations [4], The World Federation of Societies of Biological Psychiatry (WFSBP) guidelines for biological treatment of schizophrenia [6], The National Institute for Health and Care Excellence (NICE) guideline [9], and The Royal Australian and New Zealand College of Psychiatrists clinical practice guideline [7], which recommends a trial of clozapine if there is no response to two trials of different antipsychotics. 
In the KMAP-SPR 2006, the use of FGAs at Stage 2 was limited to patients who had shown a good response to FGAs in the past. However, since CATIE and CUtLASS have shown that the difference in treatment effects between SGA and FGA may not be significant, whether to use FGAs at Stage 2 is left to the judgment of the clinician.

\section{Stage 3}

If no treatment response is achieved at Stage 2, clozapine monotherapy is recommended at Stage 3. Treatment resistance is usually defined when patients with schizophrenia continue to experience clinically significant psychotic symptoms after 2 adequate trials of different antipsychotics [19]. Moreover, almost all clinical guidelines [4-9] suggest that clozapine be offered to patients with treatment-resistant schizophrenia, and this is consistent with KMAP-SPR 2019. Many clinical guidelines recommend the determination of clozapine plasma levels to guide dosage and check drug compliance, but more than half of the reviewers objected to monitoring clozapine levels. This is probably because of limited availability of testing; clozapine plasma level monitoring is not implemented in many hospitals in South Korea.

\section{Stage 4}

At Stage 4, a combination of an SGA and clozapine was the most preferred treatment. This is consistent with a recent meta-analysis, which demonstrated that this combination is modestly beneficial in patients not responding to clozapine alone [20]. However, little evidence was found for preferring one SGA over another in combination with clozapine. The reviewers preferred amisulpride, aripiprazole, and risperidone. In other research, patients who were only partially responsive to clozapine monotherapy and who received amisulpride or placebo for 6 weeks showed the beneficial effect of augmented amisulpride in the secondary measures (e.g., Clinical Global Impression) [21]. In a study comparing the effectiveness of clozapine/amisulpride and clozapine/quetiapine in patients partially responsive to clozapine, the improvement associated with amisulpride was significantly greater than that seen with quetiapine [22]. When clozapine was combined with aripiprazole, researchers observed an improvement in negative symptoms [23], or a significant improvement in positive symptoms and general psychopathology [24]. Studies on the combination of clozapine with risperidone were reported most often, but findings have been mixed: significant improvement $[25,26]$ or no proven improvement [27-29].

\section{Stage 5}

Little evidence is available to support combinations of non-clozapine antipsychotics [30], although this is common in clinical practice. Since controlled studies on combination therapy are by nature difficult to conduct, few studies have reported on combinations of antipsychotics other than those involving clozapine in treatment resistant schizophrenia [30]. At Stage 5, an SGA/FGA plus ECT, or an SGA/FGA plus another agent such as a mood stabilizer can be tried, but these treatments are likewise not based on controlled studies. However, the effects of treatment are believed to vary considerably across individuals, involving substantial improvement in some and worsening in others, although proven evidence for this is lacking. Because polypharmacy is a risk factor for severe side-effect burden [31], caution should be exercised in prescribing more than three kinds of drugs despite no apparent therapeutic benefit.

\section{LAls}

In the KMAP-SPR 2006, LAls were used in cases of poor drug compliance, but the KMAP-SPR 2019 allows clinicians to use it at their discretion. This recommendation is based on the advantages of LAls over oral antipsychotics, namely improved compliance to medication and prevention of the worsening of symptoms and relapses associated with the discontinuation of treatment [13]. Noncompliance is very common during the early stages of treatment; approximately $40 \%$ of patients stop taking their antipsychotic medication within 1 year and about $75 \%$ stop taking the medication within 2 years [32]. In patients with schizophrenia, non-compliance is problematic because it can lead to exacerbation of symptoms and relapses [33]. LAls is an important treatment option to compensate for non-compliance by making it easier to detect non-compliance and by enabling early intervention [34]. Several meta-analyses demonstrated that LAIs were superior to oral antipsychotics in preventing rehospitalization and relapse $[35,36]$. Furthermore, a study of patients with first-episode schizophrenia showed that LAls were associated with significantly lower relapse and rehospitalization rates than those of oral antipsychotics [37]. 


\section{Advantages and Limitations}

Several limitations of this study should be acknowledged. First, the study is based on a consensus of Korean experts rather than experimental evidence. Most available evidence is from RCTs. However, RCTs may not apply to real-life clinical situations because they have strict inclusion/exclusion criteria and highly controlled settings. Therefore, we drafted the revision with reference to recent clinical studies and other guidelines based on experimental evidence, but we also consulted with experts to ensure that the algorithm reflected actual clinical situations. Second, the size of the Review committee may be too small to provide a valid consensus by some criteria. However, we decided that a sample of 69 psychiatrists is sufficient based on the fact that there are only 4,525 psychiatrists in South Korea. Third, the draft algorithm made no distinction between first-episode and multiple-episode patients. Because these two kinds of patient have different treatment outcomes and clinical features, several guidelines provide different treatment recommendations for first- and multiple-episode patients [6,7]. This option should be considered in future KMAP-SPR revisions.

To our knowledge, the KMAP-SPR 2019 is the most recent guideline revision based on both recent findings and expert consensus. Moreover, the guidelines are easy to understand and apply clinically, and the treatment options allow for the exercise of judgement by the clinician. We hope that the KMAP-SPR 2019 will provide clinicians with useful information to help them in making important decisions in difficult clinical situations.

\section{Acknowledgments}

This study was supported by the Korean Society for Schizophrenia Research and the Korean College of Neuropsychopharmacology. This study was presented on October 10, 2019 at the 6th Congress of Asian College of Neuropsychopharmacology. This research did not receive any specific grant from funding agencies in the commercial sector.

\section{Conflicts of Interest}

No potential conflict of interest relevant to this article was reported.

\section{Author Contributions}

Conceptualization: Young-Chul Chung, Chan-Hyung
Kim. Data acquisition: Jung Suk Lee, Je-Yeon Yun, Shi Hyun Kang, Seung Jae Lee, Joon-Ho Choi, Beomwoo Nam, and Seung-Hwan Lee. Writing-original draft: Jung Suk Lee. Writing-review \& editing: Jung Suk Lee, ChanHyung Kim.

\section{ORCID}

Jung Suk Lee https://orcid.org/0000-0002-5401-1931 Je-Yeon Yun https://orcid.org/0000-0002-5531-2410 Shi Hyun Kang Seung Jae Lee Joon-Ho Choi https://orcid.org/0000-0001-8712-5698 Beomwoo Nam https://orcid.org/0000-0003-3648-9824 htps://orcid.org/0000-0003-3530-1746 Seung-Hwan Lee https://orcid.org/0000-0003-0305-3709 Young-Chul Chung https://orcid.org/0000-0001-9491-1822 Chan-Hyung Kim https://orcid.org/0000-0001-8419-3759

\section{REFERENCES}

1. Field MJ, Lohr KN. Guidelines for clinical practice: from development to use. Washington, D.C.:National Academy Press; 1992

2. Seo JS, Bahk WM, Wang HR, Woo YS, Park YM, Jeong JH, et al. Korean medication algorithm for depressive disorders 2017: third revision. Clin Psychopharmacol Neurosci 2018; 16:67-87.

3. Woo YS, Bahk WM, Lee JG, Jeong JH, Kim MD, Sohn I, et al. Korean medication algorithm project for bipolar disorder 2018 (KMAP-BP 2018): fourth revision. Clin Psychopharmacol Neurosci 2018;16:434-448.

4. Buchanan RW, Kreyenbuhl J, Kelly DL, Noel JM, Boggs DL, Fischer BA, et al.; Schizophrenia Patient Outcomes Research Team (PORT). The 2009 schizophrenia PORT psychopharmacological treatment recommendations and summary statements. Schizophr Bull 2010;36:71-93.

5. Barnes TR; Schizophrenia Consensus Group of British Association for Psychopharmacology. Evidence-based guidelines for the pharmacological treatment of schizophrenia: recommendations from the British Association for Psychopharmacology. J Psychopharmacol 2011;25:567-620.

6. Hasan A, Falkai P, Wobrock T, Lieberman J, Glenthoj B, Gattaz WF, et al.; World Federation of Societies of Biological Psychiatry (WFSBP) Task Force on Treatment Guidelines for Schizophrenia. World federation of societies of biological psychiatry (WFSBP) guidelines for biological treatment of schizophrenia, part 1: update 2012 on the acute treatment of schizophrenia and the management of treatment resistance. World J Biol Psychiatry 2012;13:318-378.

7. Galletly C, Castle D, Dark F, Humberstone V, Jablensky A, Killackey E, et al. Royal Australian and New Zealand College of Psychiatrists clinical practice guidelines for the manage- 
ment of schizophrenia and related disorders. Aust N Z J Psychiatry 2016;50:410-472.

8. Moore TA, Buchanan RW, Buckley PF, Chiles JA, Conley RR, Crismon ML, et al. The Texas Medication Algorithm Project antipsychotic algorithm for schizophrenia: 2006 update. J Clin Psychiatry 2007;68:1751-1762.

9. National Collaborating Centre for Mental Health (UK). Psychosis and schizophrenia in adults: treatment and management. London:National Institute for Health and Care Excellence (UK);2014.

10. Canuso CM, Battisti WP. Paliperidone extended-release: a review of efficacy and tolerability in schizophrenia, schizoaffective disorder and bipolar mania. Expert Opin Pharmacother 2010;11:2557-2567.

11. Chue $\mathrm{P}$, Chue J. A review of paliperidone palmitate. Expert Rev Neurother 2012;12:1383-1397.

12. Tenjin T, Miyamoto S, Ninomiya Y, Kitajima R, Ogino S, Miyake $\mathrm{N}$, et al. Profile of blonanserin for the treatment of schizophrenia. Neuropsychiatr Dis Treat 2013;9:587-594.

13. Salgueiro M, Segarra R. Long-acting injectable second-generation antipsychotics in first-episode psychosis: a narrative review. Int Clin Psychopharmacol 2019;34:51-56.

14. Lieberman JA, Stroup TS, McEvoy JP, Swartz MS, Rosenheck RA, Perkins DO, et al.; Clinical Antipsychotic Trials of Intervention Effectiveness (CATIE) Investigators. Effectiveness of antipsychotic drugs in patients with chronic schizophrenia. N Engl J Med 2005;353:1209-1223.

15. Jones PB, Barnes TR, Davies L, Dunn G, Lloyd H, Hayhurst KP, et al. Randomized controlled trial of the effect on quality of life of second- vs first-generation antipsychotic drugs in schizophrenia: Cost Utility of the Latest Antipsychotic Drugs in Schizophrenia Study (CUtLASS 1). Arch Gen Psychiatry 2006; 63:1079-1087.

16. Haddad PM, Brain C, Scott J. Nonadherence with antipsychotic medication in schizophrenia: challenges and management strategies. Patient Relat Outcome Meas 2014;5:43-62.

17. Strejilevich SA, Palatnik A, Avila R, Bustin J, Cassone J, Figueroa $S$, et al. Lack of extrapyramidal side effects predicts quality of life in outpatients treated with clozapine or with typical antipsychotics. Psychiatry Res 2005;133:277-280.

18. Kishimoto T, Agarwal V, Kishi T, Leucht S, Kane JM, Correll $\mathrm{CU}$. Relapse prevention in schizophrenia: a systematic review and meta-analysis of second-generation antipsychotics versus first-generation antipsychotics. Mol Psychiatry 2013; 18:53-66.

19. Suzuki T, Remington G, Mulsant BH, Uchida $H$, Rajji TK, Graff-Guerrero A, et al. Defining treatment-resistant schizophrenia and response to antipsychotics: a review and recommendation. Psychiatry Res 2012;197:1-6.

20. Taylor DM, Smith L, Gee SH, Nielsen J. Augmentation of clozapine with a second antipsychotic - a meta-analysis. Acta Psychiatr Scand 2012;125:15-24.

21. Assion HJ, Reinbold H, Lemanski S, Basilowski M, Juckel G.
Amisulpride augmentation in patients with schizophrenia partially responsive or unresponsive to clozapine. A randomized, double-blind, placebo-controlled trial. Pharmacopsychiatry 2008;41:24-28.

22. Genç Y, Taner E, Candansayar S. Comparison of clozapineamisulpride and clozapine-quetiapine combinations for patients with schizophrenia who are partially responsive to clozapine: a single-blind randomized study. Adv Ther 2007;24:1-13.

23. Chang JS, Ahn YM, Park HJ, Lee KY, Kim SH, Kang UG, et al. Aripiprazole augmentation in clozapine-treated patients with refractory schizophrenia: an 8-week, randomized, doubleblind, placebo-controlled trial. J Clin Psychiatry 2008;69: 720-731.

24. Muscatello MR, Bruno A, Pandolfo G, Micò U, Scimeca G, Di Nardo F, et al. Effect of aripiprazole augmentation of clozapine in schizophrenia: a double-blind, placebo-controlled study. Schizophr Res 2011;127:93-99.

25. Weiner E, Conley RR, Ball MP, Feldman S, Gold JM, Kelly DL, et al. Adjunctive risperidone for partially responsive people with schizophrenia treated with clozapine. Neuropsychopharmacology 2010;35:2274-2283.

26. Josiassen RC, Joseph A, Kohegyi E, Stokes S, Dadvand M, Paing WW, et al. Clozapine augmented with risperidone in the treatment of schizophrenia: a randomized, double-blind, placebo-controlled trial. Am J Psychiatry 2005;162:130-136.

27. Freudenreich O, Henderson DC, Walsh JP, Culhane MA, Goff DC. Risperidone augmentation for schizophrenia partially responsive to clozapine: a double-blind, placebo-controlled trial. Schizophr Res 2007;92:90-94.

28. Honer WG, Thornton AE, Chen EY, Chan RC, Wong JO, Bergmann A, et al.; Clozapine and Risperidone Enhancement (CARE) Study Group. Clozapine alone versus clozapine and risperidone with refractory schizophrenia. N Engl J Med 2006;354:472-482.

29. Akdede BB, Anil Yağcioğlu AE, Alptekin K, Turgut TI, Tümüklü M, Yazici MK, et al. A double-blind study of combination of clozapine with risperidone in patients with schizophrenia: effects on cognition. JClin Psychiatry 2006;67:19121919.

30. Sinclair D, Adams CE. Treatment resistant schizophrenia: a comprehensive survey of randomised controlled trials. BMC Psychiatry 2014;14:253.

31. Iversen TSJ, Steen NE, Dieset I, Hope S, Mørch R, Gardsjord $\mathrm{ES}$, et al. Side effect burden of antipsychotic drugs in real life impact of gender and polypharmacy. Prog Neuropsychopharmacol Biol Psychiatry 2018;82:263-271.

32. Perkins DO. Adherence to antipsychotic medications. J Clin Psychiatry 1999;60 Suppl 21:25-30.

33. Emsley R, Chiliza B, Asmal L, Harvey BH. The nature of relapse in schizophrenia. BMC Psychiatry 2013;13:50.

34. Stevens GL, Dawson G, Zummo J. Clinical benefits and impact of early use of long-acting injectable antipsychotics for schizophrenia. Early Interv Psychiatry 2016;10:365-377. 
35. Leucht S, Tardy M, Komossa K, Heres S, Kissling W, Salanti G, et al. Antipsychotic drugs versus placebo for relapse prevention in schizophrenia: a systematic review and metaanalysis. Lancet 2012;379:2063-2071.

36. Kishimoto T, Nitta M, Borenstein M, Kane JM, Correll CU. Long-acting injectable versus oral antipsychotics in schizophrenia: a systematic review and meta-analysis of mirror-im- age studies. J Clin Psychiatry 2013;74:957-965.

37. Subotnik KL, Casaus LR, Ventura J, Luo JS, Hellemann GS, Gretchen-Doorly D, et al. Long-acting injectable risperidone for relapse prevention and control of breakthrough symptoms after a recent first episode of schizophrenia. A randomized clinical trial. JAMA Psychiatry 2015;72:822-829. 